\title{
Effect of Chronic Continuous Normobaric Hypoxia on Functional State of Cardiac Mitochondria and Tolerance of Isolated Rat Heart to Ischemia and Reperfusion: Role of $\mu$ and $\delta_{2}$ Opioid Receptors
}

\author{
E. S. PROKUDINA ${ }^{1}$, N. V. NARYZHNAYA ${ }^{1}$, A. V. MUKHOMEDZYANOV ${ }^{1}$, \\ A. S. GORBUNOV ${ }^{1}$, Y. ZHANG ${ }^{2}$, A. S. JAGGI ${ }^{3}$, S. Y. TSIBULNIKOV ${ }^{1}$, E. A. NESTEROV ${ }^{4}$, \\ Y. B. LISHMANOV ${ }^{1,4}$, M. S. SULEIMAN ${ }^{5}$, P. R. OELTGEN ${ }^{6}$, L. N. MASLOV ${ }^{1}$
}

${ }^{1}$ Laboratory of Experimental Cardiology, Cardiology Research Institute, Tomsk National Research Medical Centre, Russian Academy of Sciences, Tomsk, Russia, ${ }^{2}$ Department of Physiology, Hebei Medical University, Shijiazhuang, China, ${ }^{3}$ Department of Pharmaceutical Sciences and Drug Research, Punjabi University Patiala, India, ${ }^{4}$ Tomsk Polytechnic University. Tomsk, Russia, ${ }^{5}$ Bristol Heart Institute, School of Clinical Sciences, Faculty of Medicine and Dentistry, University of Bristol, Bristol, United Kingdom, ${ }^{6}$ Department of Pathology, University of Kentucky College of Medicine, Lexington, KY, USA

Received May 18, 2018

Accepted July 4, 2019

Epub Ahead of Print October 25, 2019

\begin{abstract}
Summary
Chronic continuous normobaric hypoxia $(\mathrm{CNH})$ increases cardiac tolerance to ischemia/reperfusion injury in vivo and this effect is mediated via $\mu$ and $\delta_{2}$ opioid receptors (ORs) activation. $\mathrm{CNH}$ has also been shown to be cardioprotective in isolated rat heart. In this study, we hypothesize that this cardioprotective effect of $\mathrm{CNH}$ is mediated by activation of $\mu$ and $\delta_{2}$ ORs and preservation of mitochondrial function. Hearts from rats adapted to $\mathrm{CNH}$ (12\% oxygen) for 3 weeks were extracted, perfused in the Langendorff mode and subjected to $45 \mathrm{~min}$ of global ischemia and $30 \mathrm{~min}$ of reperfusion. Intervention groups were pretreated for $10 \mathrm{~min}$ with antagonists for different OR types: naloxone $(300 \mathrm{nmol} / \mathrm{l})$, the selective $\delta$ OR antagonist TIPP $(\psi)(30 \mathrm{nmol} / \mathrm{l})$, the selective $\delta_{1}$ OR antagonist BNTX $(1 \mathrm{nmol} / \mathrm{l})$, the selective $\delta_{2}$ OR antagonist naltriben $(1 \mathrm{nmol} / \mathrm{l})$, the selective peptide $\mu$ OR antagonist CTAP $(100 \mathrm{nmol} / \mathrm{l})$ and the selective $\mathrm{K}$ OR antagonist nor-binaltorphimine $(3 \mathrm{nmol} / \mathrm{l})$. Creatine kinase activity in coronary effluent and cardiac contractile function were monitored to assess cardiac injury and functional impairment. Additionally, cardiac tissue was collected to measure ATP and to isolate mitochondria to measure respiration rate and calcium retention capacity. Adaptation to $\mathrm{CNH}$ decreased myocardial creatine kinase release during reperfusion and improved the postischemic recovery of contractile function. Additionally, $\mathrm{CNH}$ improved mitochondrial state 3 and uncoupled respiration rates, ADP/O, mitochondrial transmembrane potential and calcium retention
\end{abstract}

capacity and myocardial ATP level during reperfusion compared to the normoxic group. These protective effects were completely abolished by naloxone, $\operatorname{TIPP}(\psi)$, naltriben, CTAP but not BNTX or nor-binaltorphimine. These results suggest that cardioprotection associated with adaptation to $\mathrm{CNH}$ is mediated by $\mu$ and $\delta_{2}$ opioid receptors activation and preservation of mitochondrial function.

\section{Key words}

Continuous normobaric hypoxia • Heart • Ischemia • Reperfusion - Mitochondria • Opioid receptors

\section{Corresponding author}

Leonid N. Maslov, Laboratory of Experimental Cardiology, Cardiology Research Institute, Tomsk National Research Medical Centre, Russian Academy of Sciences, Kyevskaya 111A, 634012 Tomsk, Russia. E-mail: Maslov@cardio-tomsk.ru

\section{Introduction}

Cardiac ischemia and reperfusion injury can occur during coronary angioplasty, cardiac surgery and heart transplantation (Depre and Taegtmeyer 2000) contributing to morbidity and mortality (Eltzschig and Eckle 2011). Key mediators of reperfusion injury are $\mathrm{Ca}^{2+}$ loading and generation of reactive oxygen species 
(ROS), both are known to trigger mitochondrial permeability transition pore (MPTP) opening leading to death by necrosis and/or apoptosis (Halestrap et al. 2007, Kroemer et al. 2007, Abdelwahid et al. 2017, Rasola and Bernardi, 2011, Ong et al. 2015). It has been established that the MPTP blocker cyclosporine A can prevent necrosis of cardiomyocytes during ischemia/reperfusion of the heart (Hausenloy et al. 2014). Acute interventions including cardioplegic arrest during open heart surgery confer partial protection against the damaging effects of ischemia/reperfusion (I/R). Therefore, the search continues for strategies that can further reduce $\mathrm{I} / \mathrm{R}$ injury.

One interesting intervention involves an adaptive response to long-term continuous normobaric hypoxia $(\mathrm{CNH})$ which has been shown to increase cardiac tolerance to the impact of I/R. For example, hearts of rats treated with $\mathrm{CNH}$ have reduced infarct size in response to ischemia and reperfusion in vivo (Neckar et al. 2003, Maslov et al. 2013) and in vitro (Maslov et al. 2015). Cardioprotection was associated with a preservation of the rate of respiration of mitochondria in state 3 , and improves the resistance of the MPTP to $\mathrm{Ca}^{2+}$ overload (Maslov et al. 2015). These effects did not appear after the blockade of opioid receptors (OR) with naloxone (Maslov et al. 2015). However, it is still unclear which opioid receptor subtypes are activated following $\mathrm{CNH}$ exposure leading to improvement in the functional state of mitochondria and the heart during reperfusion. Previously, we showed that the infarct size-limiting effect of $\mathrm{CNH}$ in vivo depends on the activation of $\mu$ and $\delta_{2}$ OR (Maslov et al. 2013), so we hypothesized that the improvement of heart contractility in the reperfusion period after adaptation also depends upon the activation of these ORs. Improvement of the functional state of mitochondria could also be a consequence of activation of $\mu$ and $\delta_{2}$ OR.

The objective of the present study was to assess the role of the opioid receptor subtypes in improving the functional state of the heart and mitochondria during reperfusion after adaptation to continuous normobaric hypoxia.

\section{Methods}

Male Wistar rats weighing 250-300 g were housed at $23 \pm 1{ }^{\circ} \mathrm{C}$ with a relative humidity of $60-70 \%$ and a 12-h light/dark cycle with free access to water and standard rat chow. Experimental animals were exposed for 3 weeks to continuous hypoxia $\left(12 \% \mathrm{O}_{2}\right)$ in a normobaric chamber equipped with a hypoxia generator Bio-Nova-204G4R1 (NTO Bio-Nova, Moscow, Russia) as described previously (Maslov et al. 2015). Construction of the chamber allowed for cage cleaning and food and water replacement without exposing the animals to room air during adaptation to hypoxia. Normoxic animals (control) were kept in room air for the same period of time. The study was approved by the Ethical Committee of the Cardiology Research Institute, Tomsk National Research Medical Centre and were performed in compliance with the National Institutes of Health Guide for the Care and Use of Laboratory Animals (National Research Council, The National Academies Press, Washington, DC).

\section{Ischemia and reperfusion of isolated hearts}

Rats were killed by cervical dislocation at room air within $24 \mathrm{~h}$ after the termination of hypoxic exposure, in order to exclude the effect of acute hypoxia/reoxygenation on cardiac resistance to ischemia. The hearts were rapidly excised and perfused according to Langendorff under constant pressure $(52 \mathrm{mmHg})$ with a non-recirculating gassed $\left(\begin{array}{llllll}95 \% & \mathrm{O}_{2} & \text { and } & 5 \% & \mathrm{CO}_{2}\end{array}\right)$ Krebs-Henseleit (K-H) solution containing (mmol/l): $\mathrm{NaCl} 120, \mathrm{NaHCO}_{3} 20, \mathrm{KCl} 4.8, \mathrm{MgSO}_{4} 1.2, \mathrm{KH}_{2} \mathrm{PO}_{4}$ 1.2, $\mathrm{CaCl}_{2} 2.0$, and glucose $10 \quad\left(37^{\circ} \mathrm{C}, \mathrm{pH}\right.$ 7.5). Contractile function was measured with a water filled latex balloon inserted into the LV and connected by a metal cannula to a SS13L pressure transducer (Biopac System, Goleta, CA, USA). Heart rate (HR), left ventricular systolic pressure (LVSP), and diastolic pressure (LVDP) were recorded by an MP35 (Biopac System). Developed pressure (LVDevP) was calculated as a difference between LVSP and LVDP. During the 20-min equilibration period, diastolic pressure was gradually adjusted to $10-12 \mathrm{mmHg}$. The hearts were then subjected to $45 \mathrm{~min}$ of global no-flow normothermic ischemia followed by $30 \mathrm{~min}$ of reperfusion. Rate pressure product was calculated as LVDevP x HR/1000.

The coronary effluent was collected during reperfusion to measure creatine kinase $(\mathrm{CK})$ release. $\mathrm{CK}$ activity was determined with a CK-NAc kit (Analyticon Biotechnologies, Lichtenfels, Germany) using a SmartSpec Plus Spectrophotometer (Bio-Rad, Hercules, CA, USA) at wavelength of $340 \mathrm{nmol} / 1$ and expressed as units per gram of heart weight for the 30-min collection period. Perfused hearts not subjected to I/R served as controls. 


\section{Pharmaceutical compounds used in the study}

To investigate the involvement of cardiac opioid receptors (ORs) in the implementation of the cardioprotective action of adaptation to $\mathrm{CNH}$, perfusion of isolated rat hearts was performed using the OR antagonists added $10 \mathrm{~min}$ prior to global ischemia. The non-selective antagonist of all types of OR naloxone was used at a final concentration of $300 \mathrm{nmol} / \mathrm{l}$ (Maslov et al. 2015). The selective peptide $\delta$ OR antagonist $\operatorname{TIPP}(\psi)$ was used at a final concentration of $30 \mathrm{nmol} / 1$ (Schiller et al. 1993). The selective $\delta_{1}$ OR antagonist 7-benzylidenenaltrexone maleate (BNTX) was used at a final concentration of $1 \mathrm{nmol} / 1$ (Portoghese et al. 1992, Sanchez-Blazquez et al. 1999). The selective $\delta_{2}$ OR antagonist naltriben mesylate was used at a final concentration of $1 \mathrm{nmol} / 1$ (Buzas et al. 1994, SanchezBlazquez et al. 1999, Tang et al. 1994). The selective peptide $\mu$ OR antagonist CTAP was used at a final concentration of $100 \mathrm{nmol} / 1$ (Garcia-Barrado et al. 2002, Ortiz-Miranda et al. 2003, Scherrer et al. 2004). The selective $\kappa$ OR antagonist nor-binaltorphimine dihydrochloride was used at a concentration of $3 \mathrm{nmol} / \mathrm{l}$ (Heijna et al. 1990). Naloxone, TIPP( $\psi)$, CTAP, norbinaltorphimine were dissolved in K-H solution. Naltriben and BNTX were dissolved in DMSO. The final concentration of DMSO in K-H solution was $0.01 \%$. Our preliminary experiments showed that this concentration of DMSO does not affect cardiac contractility and the resistance to I/R. Naloxone and nor-binaltorphimine were purchased from Sigma-Aldrich (USA). BNTX, naltriben were purchased from Tocris Bioscience (Bristol, UK). CTAP and $\operatorname{TIPP}(\psi)$ were provided by Multiple Peptide Systems (San Diego, CA, USA).

\section{Isolation of mitochondria}

Mitochondria were isolated from hearts subjected to I/R as described by Chen et al. (2002) and Argaud et al. (2005). Hearts perfused for $95 \mathrm{~min}$ and not subjected to $\mathrm{I} / \mathrm{R}$ served as controls. Ventricular myocardium was minced and homogenized with an UltraTurrax T10 with a dispersed element S10N-5G (IKAWerke, Staufen, Germany) in 20-ml isolation buffer containing (mmol/l): sucrose 70, mannitol 210, EGTA 6, HEPES 10 and bovine serum albumin (BSA) fatty acid free $5 \mathrm{mg} / \mathrm{ml}$ ( $\mathrm{pH} \mathrm{7.4)}$. The homogenate was centrifuged at $900 \mathrm{~g}$ for $10 \mathrm{~min}$, and the supernatant was collected, filtered through a nylon filter with a pore diameter of $0.5 \mathrm{~mm}$, and centrifuged again at $9000 \mathrm{~g}$ for $10 \mathrm{~min}$ using centrifuge Eppendorf 5810 R (Eppendorf AG, Hamburg,
Germany). The resulting pellet was resuspended in $20 \mathrm{ml}$ isolation buffer with $0.1 \mathrm{mmol} / \mathrm{l}$ EGTA and centrifuged at $9000 \mathrm{~g}$ for $10 \mathrm{~min}$. The final mitochondrial pellet was resuspended in $200 \mu \mathrm{l}$ buffer without EGTA. All steps were performed at $4{ }^{\circ} \mathrm{C}$. Protein concentration in the mitochondrial suspension was determined by the method of Bradford (Bradford et al. 1976).

\section{Mitochondrial respiration}

The mitochondrial respiration rate was measured at $25^{\circ} \mathrm{C}$ with a Clark-type electrode DKTP 02.4 (EkonixExpert, Moscow, Russia) in a continuously magnetically stirred thermostatic chamber using oxygraph Expert-001 (Ekonix-Expert, Moscow, Russia). Mitochondria $(0.35 \mathrm{mg}$ protein $/ \mathrm{ml})$ were incubated in a buffer containing $100 \mathrm{mmol} / 1$ sucrose, $10 \mathrm{mmol} / 1 \mathrm{Tris}-\mathrm{HCl}$, $5 \mathrm{mmol} / \mathrm{l} \quad \mathrm{KH}_{2} \mathrm{PO}_{4}, 0.10 \mathrm{mmol} / \mathrm{l}$ EGTA, $3 \mathrm{mmol} / \mathrm{l}$ pyruvate, and $3 \mathrm{mmol} / \mathrm{l}$ malate (pH 7.37) (Singh et al. 2006). Respiration was measured sequentially in state 2 (substrates only), state 3 (in the presence of ADP, $200 \mathrm{nmol} / \mathrm{l}$ ), and state 4 (after phosphorylation of all added ADP to ATP) according to Chance and Williams (1955). ADP/O ratios were calculated. For the measurement of maximum respiration of uncoupled mitochondria, $100 \mathrm{nmol} / 1$ carbonyl cyanide-4-(trifluoromethoxy) phe-nylhydrazone (FCCP) was added to the chamber. Respiration rate was expressed as nmol $\mathrm{O}_{2}$ per mg protein per min.

Determination of mitochondrial membrane potential $(\Delta \Psi)$

$\Delta \Psi$ was measured by a spectrofluorimeter Shimadzu RF-5301-PC (Shimadzu Corporation, Kyoto, Japan) by transmembrane distribution of the fluorescence indicator tetramethylrhodamineethyl ester (TMRE, Molecular Probes, Invitrogen, Eugene, USA) (Paillard et al. 2009, Scaduto and Grotyohann 1999, Singh et al. 2006). The excitation wavelength $\lambda E x$ was $550 \mathrm{~nm}$, the emission wavelength $\lambda E \mathrm{Em}$ was $575 \mathrm{~nm}$. The reaction was initiated by the addition of a mitochondrial suspension ( $2 \mathrm{mg}$ protein) to a cuvette of the spectrofluorimeter to a $3 \mathrm{ml}$ buffer containing $200 \mathrm{mM}$ sucrose, $10 \mathrm{mM}$ Tris$\mathrm{HCl}, 5 \mathrm{mM} \mathrm{KH} \mathrm{PO}_{4}, 0.01 \mathrm{mM}$ EGTA, $2.5 \mathrm{mg} / \mathrm{ml}$ BSA fatty acid free, $3 \mathrm{mmol} / \mathrm{l}$ pyruvate and $3 \mathrm{mmol} / 1$ malate $\left(\mathrm{pH} 7.37,25^{\circ} \mathrm{C}\right.$ ), $40 \mathrm{nmol} / \mathrm{l} \mathrm{TMRE}$. The value of $\Delta \Psi$ was estimated from the fall in fluorescence intensity after addition of $100 \mathrm{nmol} / \mathrm{l} \mathrm{FCCP}$ to the incubation medium. The magnitude of the mitochondrial transmembrane potential was presented as the fluorescence intensity 
difference before and after addition of FCCP and expressed as a percentage of the mitochondrial fluorescence of the intact (not subjected to I/R) heart in terms of $\mathrm{mg}$ protein of the mitochondria suspension.

\section{Mitochondrial calcium retention capacity (CRC)}

The mitochondrial CRC was determined with fluorescent $\mathrm{Ca}^{2+}$-sensitive indicator calcium green-5N (Molecular Probes, Invitrogen, Eugene, OR USA) using a spectrofluorimeter Shimadzu RF-5301-PC (Shimadzu Corporation, Kyoto, Japan) at excitation/emission wavelengths of 506/535 nm (Gomez et al. 2008, Singh et al. 2006). The isolated mitochondria (1 $\mathrm{mg}$ protein $/ \mathrm{ml})$ were incubated at $25^{\circ} \mathrm{C}$ in the buffer used for the measurement of respiration, the concentration of calcium green was $100 \mathrm{nmol} / \mathrm{l}$. After 2-min incubation, $100 \mathrm{nmol} \mathrm{CaCl}_{2}$ was added every $3 \mathrm{~min}$, causing fluorescence flashes that decreased slowly as a result of mitochondrial $\mathrm{Ca}^{2+}$ uptake. The $\mathrm{CaCl}_{2}$ solution was added until a massive increase in fluorescence indicated a cessation of $\mathrm{Ca}^{2+}$ uptake and MPTP opening. The mitochondrial $\mathrm{CRC}$ was calculated as a maximum amount of $\mathrm{Ca}^{2+}$ accumulated in mitochondria and expressed as nmol/mg protein (Gomez et al. 2008).

\section{Determination of the content of ATP in the myocardium}

Myocardial samples weighing 80-100 mg were excised from the left ventricle, frozen and homogenized in liquid nitrogen, adding $2 \mathrm{ml}$ of $3 \%$ trichloroacetic acid, cooled to $2^{\circ} \mathrm{C}$. The homogenate was centrifuged for $10 \mathrm{~min}$ at $3000 \mathrm{~g}$ and a temperature of $2^{\circ} \mathrm{C}$. The supernatant was neutralized with $1 \mathrm{M}$ Trizma base, the volume of the sample was adjusted to $2 \mathrm{ml}$ with water (Chida et al. 2012). ATP measurement was performed using the ATP Bioluminescent Assay Kit (SigmaAldrich, USA) and a Lucy-2 chemiluminometer (Anthos Labtec Instruments, Salzburg, Austria).

\section{Reagents}

All reagents were purchased from SigmaAldrich (St Louis, MO, USA), except for chemicals used to prepare K-H buffer, which were obtained from MP Biomedicals (Irvine, CA, USA). Distilled water was additionally purified with the device "Simplicity" (Millipore, France).

\section{Statistical analysis}

Results are expressed as mean \pm SEM from indicated number of experiments. Data analysis was performed using GraphPad Prism 6.0 software (GraphPad
Software, San Diego, CA, USA). One-way ANOVA with Newman-Keuls post hoc test was used to detect betweengroup differences. Values exceeding the $95 \%$ probability limits $(\mathrm{P}<0.05)$ were considered significant.

\section{Results}

The effect of OR antagonists on CNH-induced cardioprotection against I/R injury

Myocardial injury caused by $\mathrm{I} / \mathrm{R}$ was assessed by measuring the level of $\mathrm{CK}$ released to the coronary effluent during reperfusion compared to that of the hearts not subjected to $\mathrm{I} / \mathrm{R}$. In $\mathrm{CNH}$ hearts, the $\mathrm{CK}$ release was 2.5-fold lower than in the control normoxic group (Fig. 1). Naloxone, TIPP $(\psi)$, naltriben or CTAP eliminated the cardioprotective effect of $\mathrm{CNH}$, whereas BNTX and nor-binaltorphimine had no effect (Fig. 1). None of the OR antagonists affected CK release from the hearts of normoxic rats.

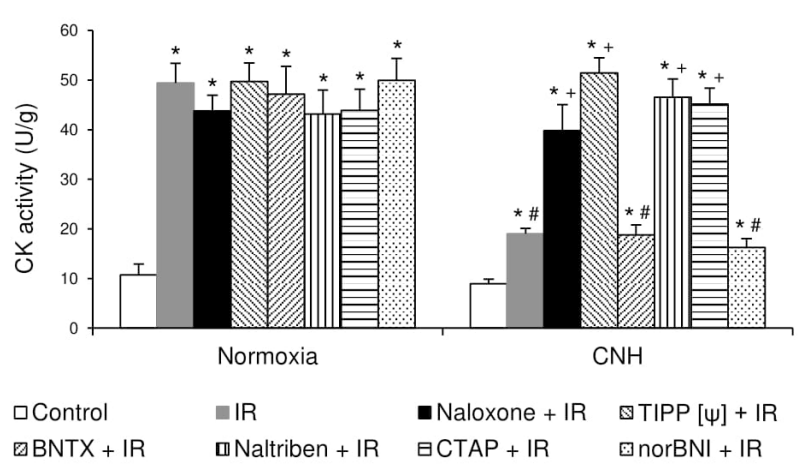

Fig. 1. Effects of ischemia/reperfusion (IR) on creatine kinase (CK) activity in the coronary effluent from pretreated with OR antagonists and untreated isolated hearts of non-adapted (Normoxia) and adapted to chronic hypoxia $(\mathrm{CNH})$ rats. Values are mean \pm SEM from 12 hearts in each group. $* \mathrm{P}<0.05$ versus corresponding non-ischemic (control) group. \# $\mathrm{P}<0.05$ versus corresponding normoxic group with IR. ${ }^{+} \mathrm{P}<0.05$ versus adapted to $\mathrm{CNH}$ group with IR.

The effect of OR antagonists on CNH-induced cardioprotection against post-ischemic contractile dysfunction

There were no differences in the value of LVDP, LVDevP and HR between hearts of normoxic and CNHadapted animals before the ischemic insult. In the normoxic group, LVDevP recovered to $20 \pm 2 \%$ of the pre-ischemic value after $30 \mathrm{~min}$ of reperfusion compared to $64 \pm 8 \%$ in the $\mathrm{CNH}$ group. LVDP was increased by approximately $100 \%$ in $\mathrm{CNH}$ and by $300 \%$ in normoxic rats after I/R (Fig. 2A, B). Naloxone, $\operatorname{TIPP}(\psi)$, naltriben 
or CTAP abolished the CNH-induced cardioprotection, whereas BNTX and no-binaltorphimine had no effect (Fig. 2A, B). None of the OR antagonists affected postischemic dysfunction in the hearts of normoxic rats. $\mathrm{CNH}$ improved recovery of rate pressure product (Fig. 2C), while the OR antagonists naloxone, $\operatorname{TIPP}(\psi)$, naltriben or CTAP eliminated this effect.
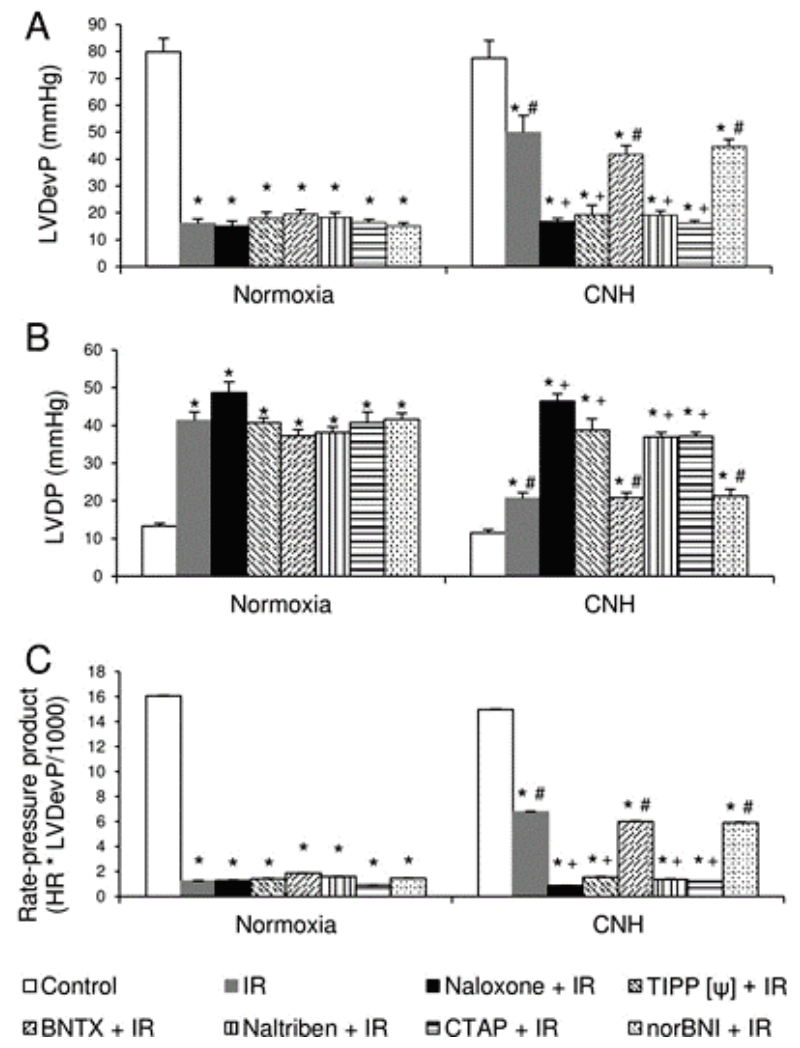

Fig. 2. Post-ischemic recovery of (A) left ventricular developed pressure (LVDP), (B) left ventricular end-diastolic pressure (LVEDP) and (C) heart rate in pretreated with OR-antagonists and untreated isolated hearts of non-adapted (Normoxia) and adapted to chronic hypoxia $(\mathrm{CNH})$ rats. Values are mean $\pm \mathrm{SEM}$ from 12 hearts in each group. I/R, ischemia/reperfusion. $* \mathrm{P}<0.05$ versus corresponding non-ischemic (control) group. ${ }^{*} \mathrm{P}<0.05$ versus corresponding normoxic group with IR. ${ }^{+} \mathrm{P}<0.05$ versus adapted to $\mathrm{CNH}$ group with IR.

The effect of OR antagonists on mitochondrial respiration

In experiments with mitochondria isolated from hearts not subjected to $I / R$, we found that there was no effect of $\mathrm{CNH}$ on the state $3\left(\mathrm{~V}_{3}\right)$ respiration rate and the maximal respiration rate after an addition of FCCP to the incubation medium (Fig. 3A, B). $\mathrm{I} / \mathrm{R}$ resulted in approximately a $33 \%$ decrease in $\mathrm{V}_{3}$ in normoxic rats and a $10 \%$ decrease in $\mathrm{CNH}$. Unlike BNTX and norbinaltorphimine, naloxone, $\operatorname{TIPP}(\psi)$, naltriben or CTAP eliminated the improvement of post-ischemic respiration rates induced by $\mathrm{CNH}$ (Fig. 3A, B). None of the OR antagonists affected the $\mathrm{I} / \mathrm{R}$-induced drop of respiration in mitochondria from the hearts of normoxic rats.

We did not find any difference in state 2 (before ADP) and state 4 (after ATP synthesis) respiration rates between mitochondria from normoxic and $\mathrm{CNH}$ rats before and after I/R (data not shown).

$\mathrm{CNH}$ did not affect the $\mathrm{ADP} / \mathrm{O}$ ratio in mitochondria from the hearts not subjected to I/R. After reperfusion, $\mathrm{ADP} / \mathrm{O}$ ratio decreased from 2.31 to 1.50 in the normoxic group and from 2.32 to 2.17 in the $\mathrm{CNH}$ group (Fig. 3C). Pretreatments with naloxone, $\operatorname{TIPP}(\psi)$, naltriben or CTAP reversed the protective effect of $\mathrm{CNH}$ on $\mathrm{ADP} / \mathrm{O}$, whereas BNTX and nor-binaltorphimine had no effect. The ADP/O ratio was not affected by OR antagonists in the normoxic group.
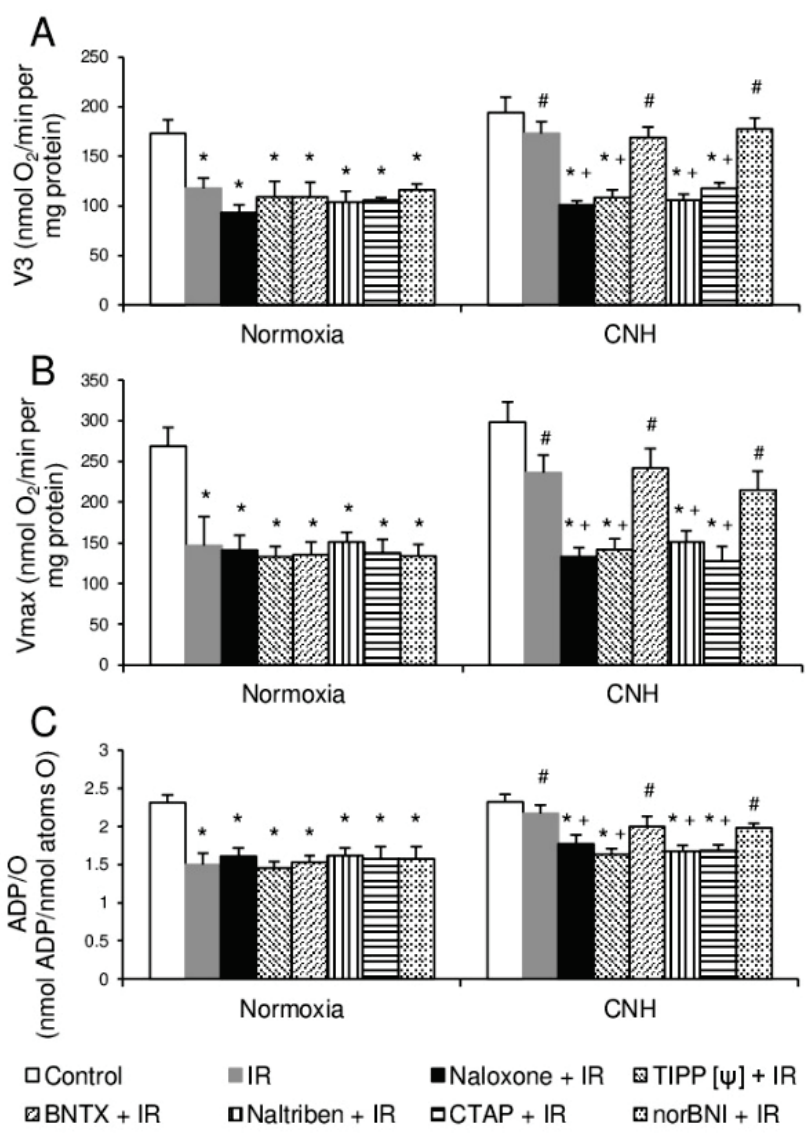

Fig. 3. Effects of ischemia/reperfusion (IR) on (A) state 3 (V3), (B) uncoupled (maximum) respiration (Vmax) rates and (C) ADP/O ratio in mitochondria from pretreated with OR-antagonists and untreated isolated hearts of non-adapted (Normoxia) and adapted to chronic hypoxia $(\mathrm{CNH})$ rats. Values are mean \pm SEM from 12 hearts in each group. $* \mathrm{P}<0.05$ versus corresponding nonischemic (control) group. ${ }^{\#} \mathrm{P}<0.05$ versus corresponding normoxic group with IR. ${ }^{+} \mathrm{P}<0.05$ versus adapted to $\mathrm{CNH}$ group with IR. 
The effect of OR antagonists on mitochondrial membrane potential

$\mathrm{CNH}$ did not affect transmembrane potential of the mitochondria $(\Delta \psi)$ from the hearts not subjected to I/R. After I/R, $\Delta \psi$ decreased by 2.5 -fold in the normoxic group and by $18 \%$ in the $\mathrm{CNH}$ group (Fig. 4A). Pretreatment with naloxone, $\operatorname{TIPP}(\psi)$, naltriben or CTAP reversed the effect of $\mathrm{CNH}$ on $\Delta \psi$. BNTX and norbinaltorphimine had no effect (Fig. 4A). None of the OR antagonists influenced the drop of $\Delta \psi$ in the normoxic group.
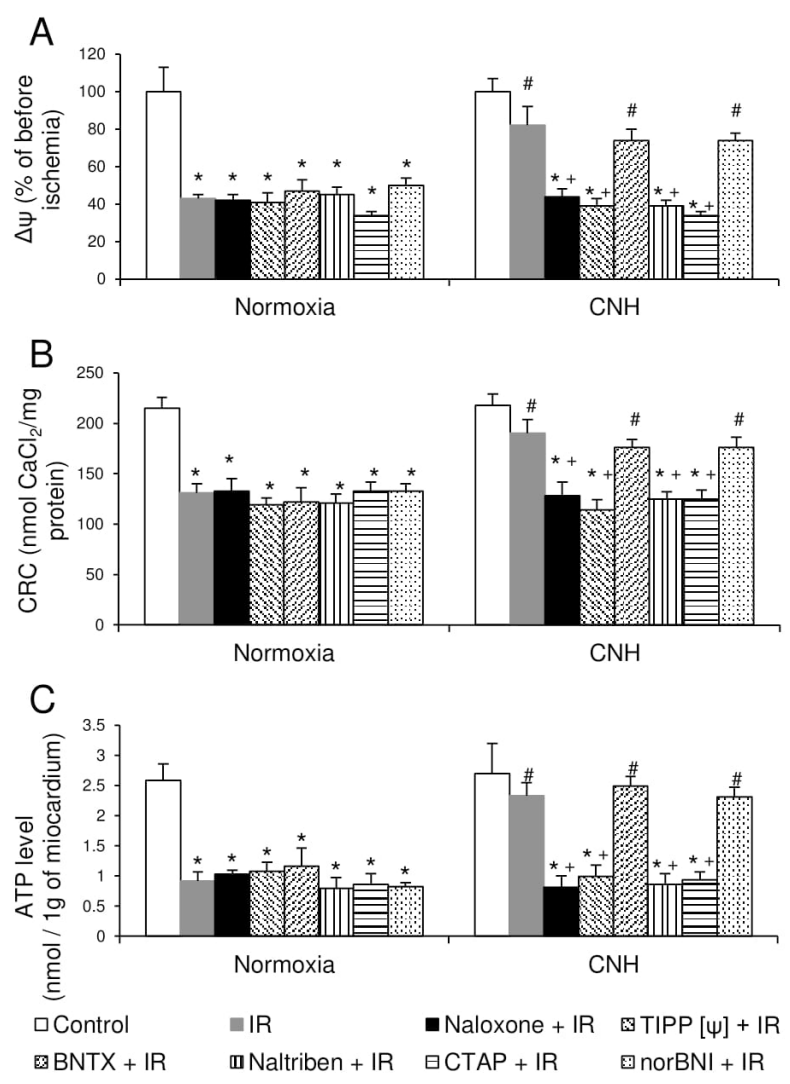

Fig. 4. Effects of ischemia/reperfusion (IR) on (A) mitochondrial membrane potential $(\Delta \Psi)$, (B) mitochondrial calcium retention capacity (CRC) and (C) content of ATP in the myocardium in pretreated with OR-antagonists and untreated isolated hearts of non-adapted (Normoxia) and adapted to chronic hypoxia (CNH) rats. Values are mean \pm SEM from 12 hearts in each group. $* \mathrm{P}<0.05$ versus corresponding non-ischemic (control) group. ${ }^{*} \mathrm{P}<0.05$ versus corresponding normoxic group with IR. ${ }^{+} \mathrm{P}<0.05$ versus adapted to $\mathrm{CNH}$ group with IR.

The effect of OR antagonists on mitochondrial calcium retention capacity

$\mathrm{CNH}$ did not affect the CRC of mitochondria isolated from the hearts not subjected to I/R. After I/R, the CRC decreased by $39 \%$ and $13 \%$ in control and $\mathrm{CNH}$ groups, respectively (Fig. 4B). Pretreatment with naloxone, TIPP $(\psi)$, naltriben or CTAP reversed the effect of $\mathrm{CNH}$ on CRC, whereas BNTX and norbinaltorphimine did not (Fig. 4B). The decrease in CRC after $\mathrm{I} / \mathrm{R}$ in the normoxic group was not affected by the OR antagonists.

\section{The effect of OR antagonists on myocardial ATP level}

Adaptation to $\mathrm{CNH}$ did not affect the myocardial ATP level if the heart was not subjected to I/R. After I/R, the ATP level in hearts of normoxic rats was reduced by $64 \%$, and in the hearts of $\mathrm{CNH}$ rats by only $14 \%$ (Fig. 4C). Unlike BNTX and nor-binaltorphimine, naloxone, $\operatorname{TIPP}(\psi)$, naltriben or CTAP abolished the $\mathrm{CNH}$-induced protection of ATP level (Fig. 4C). The drop of ATP caused by $\mathrm{I} / \mathrm{R}$ was not affected by the OR antagonists in the normoxic group.

\section{Discussion}

In this study, we provide evidence showing that chronic continuous normobaric hypoxia does not change cardiac or mitochondrial function but confers significant protection against $\mathrm{I} / \mathrm{R}$ in jury. This protection is mediated via $\mu$ and $\delta 2$ OR activation which can be responsible for preservation of mitochondrial function.

Chronic continuous normobaric hypoxia does not alter cardiac contractility or mitochondrial function

$\mathrm{CNH}$ does not alter basal cardiac contractility before induction of $\mathrm{I} / \mathrm{R}$ (Fig. 2). This result is consistent with the data of other researchers who, after adaptation of animals to hypoxia, also found no changes in the basal parameters of cardiac contractility before I/R (Tajima et al. 1994, Eells et al. 2000, Fitzpatrick et al. 2005, Wang et al. 2012, Bu et al. 2015, Neckar et al. 2002). These data coincide with the results of our previous study, where we used CNH (Maslov et al. 2015).

Regarding mitochondrial function, baseline rates of respiration did not differ between the groups of normoxic and CNH-adapted animals which is in agreement with our previous observation (Maslov et al. 2015). According to our data, in the period of previous ischemia $\mathrm{CNH}$ did not affect $\mathrm{ADP} / \mathrm{O}, \mathrm{CRC}$, ATP level in myocardial tissue. Similar data were obtained by others in rats adapted to hypoxia $\left(\mathrm{PO}_{2}=84 \mathrm{mmHg}, 6 \mathrm{~h} /\right.$ day for 42 days) (Zhu et al. 2006). In Zhu's study, a decrease in the rate of respiration was noted only in state 4 (after the synthesis of ATP). Other investigators also found that there was no effect of $\mathrm{CNH}$ on respiration rates in 
mitochondria isolated from spontaneously hypertensive rats (Neckar et al. 2017). These findings are markedly different from our data. Our studies indicate that adaptation to hypoxia can alter mitochondrial respiration. In 2004, it was demonstrated that hypoxia $\left(11 \% \mathrm{O}_{2}\right.$ for 7 days) causes a decrease in the rate of mitochondrial respiration in state 3 and a decrease in the rate of ATP synthesis in mitochondria isolated from rat hearts (Essop et al. 2004). Gross's group (Eells et al. 2000) showed an increase in the ATP synthesis rates by mitochondria isolated from the myocardium of newborn rabbits adapted to chronic normobaric hypoxia (12\% $\mathrm{O}_{2}$ for 7-10 days). Zungu et al. (2007) found that adaptation of rats to hypobaric hypoxia $\left(11 \% \mathrm{O}_{2}\right.$ for 14 days $)$ leads to a decrease in the respiration rate in state 2 (prior to incubation with ADP) and an increase in respiration rate in state 3 (after addition of ADP). However, these changes were observed only in mitochondria isolated from the right ventricle. The parameters of the respiration of mitochondria isolated from the left ventricle did not differ from the values characteristic of non-adapted animals. The authors found that adaptation to hypoxia did not affect ADP/O and the rate of ATP synthesis (Zungu et al. 2007). In another study, Heather et al. (2012), used a model of chronic normobaric hypoxia in rats $\left(11 \% \mathrm{O}_{2}\right.$ for 14 days), and showed a decrease in the rate of respiration of mitochondria in state 3 , and increases in the rate of ATP synthesis. The reason for the contradictory nature of the aforementioned data on the effect of chronic hypoxia on the respiration of the mitochondria of the intact heart remains unclear.

\section{CNH protects the heart and preserves mitochondrial function following $I / R$}

The exposure to $\mathrm{I} / \mathrm{R}$ reduced the mitochondrial state 3 respiration, uncoupled respiration, ADP/O, $\Delta \psi$ and myocardial APT level and CRC in control rats. The probable cause is the slowing down of the respiratory chain work and damage to the inner mitochondrial membrane (Sanderson et al. 2013). These changes were pronounced in mitochondria isolated from the myocardium of normoxic rats whereas adaptation to $\mathrm{CNH}$ significantly increased the tolerance of mitochondria to the I/R-induced damage. Similar data were obtained by Wang et al. (2012), who performed experiments on rats adapted to chronic intermittent hypobaric hypoxia (CIHH). They found that $\mathrm{CIHH}$ promoted a recovery of ATP content in the myocardium during reperfusion. At the same time, ATP synthase activity and $\Delta \psi$ were increased. Respiratory control ratio was higher in mitochondria from adapted $\mathrm{CNH}$ rats. The preservation of mitochondrial respiration $\left(\mathrm{V}_{3}, \mathrm{~V}_{\max }\right)$ after $\mathrm{I} / \mathrm{R}$ in rats adapted to $\mathrm{CNH}$ was also demonstrated in our previous study (Maslov et al. 2015).

Furthermore, we showed that adaptation to $\mathrm{CNH}$ contributed to the preservation of the CRC of myocardial mitochondria after I/R of isolated heart (Fig. 4B), which indicates an increased resistance of MPTP to the opening due to calcium loading. These data are consistent with our earlier report (Maslov et al. 2015). However, adaptation to hypoxia did not alter the CRC of the mitochondria isolated from hearts not subjected to $I / R$. This indicates that there is no direct effect of adaptation to $\mathrm{CNH}$ on the sensitivity of MPTP to calcium ions. However, it has also been demonstrated that $\mathrm{CNH}$ increases the tolerance of mitochondria to $\mathrm{Ca}^{2+}$-induced swelling (Neckar et al. 2017). Such a finding suggests that the tolerance of MPTP to $\mathrm{Ca}^{2+}$ can still increase.

The effect of adaptation to hypoxia on the MPTP state was also studied in experiments on neonatal male rats exposed to $\mathrm{CIHH}$ for 42 days prior to $\mathrm{I} / \mathrm{R}$ of isolated rat heart ( $\mathrm{Bu}$ et al. 2015). Interestingly, along with an increase in the resistance of the mitochondria to the opening of the MPTP, the authors reported an increase in the activity of antioxidant defense enzymes in the left ventricle ( $\mathrm{Bu}$ et al. 2015). It is known that the oxidative stress that develops during $\mathrm{I} / \mathrm{R}$ promotes the MPTP opening and increases the apoptotic death of cardiomyocytes (Seidlmayer et al. 2015). It has been established that ischemia/reperfusion of the heart can also induce necrosis of cardiomyocytes through MPTP opening (Hausenloy et al. 2014). Therefore, it is likely that increased inactivation of reactive oxygen species with antioxidant enzymes reduces the sensitivity of MPTP to calcium and prevents its premature opening in animals adapted to chronic hypoxia.

Our hypothesis is that the preservation of mitochondrial function in adapted rats during reperfusion contributes to the rapid recovery of ATP level in the myocardium and, as a result, contributes to the improvement of heart contractility during reperfusion and to the reduction of necrosis of cardiomyocytes. It is also well known that $\mathrm{Ca}^{2+}$-overloading of cardiomyocytes develops during ischemia-reperfusion of the heart (Ostadal and Kolar 1999). The increase in CRC after $\mathrm{CNH}$ contributes to the reduction of negative manifestations of $\mathrm{Ca}^{2+}$-overloading of cardiomyocytes, which in turn contributes to the improvement of heart 
contractility during reperfusion.

The cardioprotective effect of $\mathrm{CNH}$ is mediated via $\mu$ and $\delta_{2}$ OR activation

The main goal of our study was to assess the role of opioid receptors in the cardioprotective and bioenergetics effects of $\mathrm{CNH}$ in isolated hearts subjected to $\mathrm{I} / \mathrm{R}$. Our earlier work has shown that naloxone eliminates the beneficial effect of $\mathrm{CNH}$ on mitochondrial respiration and CRC after I/R (Maslov et al. 2015). However, the involvement of receptor subtypes was not addressed. We addressed this issue in the present study using different $\mathrm{OR}$ antagonists. Interestingly none of the OR antagonists affected the CK release, cardiac contractile function, and the bioenergetic state of the heart during reperfusion in experiments performed on the hearts of normoxic rats. This observation further supports our earlier data (Maslov et al. 2013, 2015) suggesting that endogenous opioids are not involved in the regulation of cardiac resistance to $\mathrm{I} / \mathrm{R}$ in naïve animals.

It has been shown that $\delta_{1}, \delta_{2}, \kappa_{1}$ OR agonists increase cardiac tolerance to I/R (Headrick et al. 2015, Maslov et al. 2009, 2016, Peart et al. 2003, Peart and Gross, 2004, Tsibulnikov et al. 2015). Concerning the role of $\mu$ OR in cardioprotection, the data are contradictory. Some studies have been shown that selective $\mu$ agonists do not affect infarct size in vivo (Maslov et al. 2010, Mukhomedzyanov et al. 2016, Schultz et al. 1998). On the other hand, the selective $\mu_{2}$ OR agonist endomorphin-1 reduced myocardial infarction in another study (Zhang et al. 2016). Eribis peptide 94 has been reported to decrease infarct size primarily via activation of $\mu$ opioid receptors (Gross et al. 2012). Therefore, it can be assumed that endogenous agonists of $\mu$ OR also can be involved in the infarctlimiting effect of $\mathrm{CNH}$.

We have shown earlier that the improved postischemic recovery of contractility in $\mathrm{CNH}$ isolated hearts is associated with the activation of OR, because naloxone eliminated this protective effect (Maslov et al. 2015). In addition, we have found that the infarct-reducing effect of $\mathrm{CNH}$ depends on the activation of $\mu$ and $\delta_{2}$ OR by endogenous opioid peptides under in vivo conditions (Maslov et al. 2013). However, it remained unclear where these OR subtypes are located in the heart or in other organs, for example, in the brain. There is evidence that activation of central opioid receptors also increases the heart's tolerance to ischemia and reperfusion (Gross et al. 2012, Wong et al. 2012). The results of the present study further extend these observations suggesting that the $\mathrm{CNH}$-induced decrease in $\mathrm{CK}$ release, improved contractile function recovery, and the restoration of mitochondrial function including desensitization of MPTP to opening in post-ischemic isolated hearts and it was dependent upon the activation of $\mu$ and $\delta_{2}$ ORs located in the heart. The effector structure of the cardioprotective effect of $\mathrm{CNH}$ is likely mitochondria. Indeed, we have shown earlier that there is a positive correlation between state 3 respiration rate and the recovery of LVDevP during reperfusion (Maslov et al. 2015). The role of mitochondria as the hypothetical end effector of opioid-induced preconditioning, ischemic preconditioning and postconditioning has been discussed others (Cohen and Downey 2011, Headrick et al. 2015, Heusch 2015, Maslov et al. 2016). However, it is unclear how the signal transmits from ORs to the mitochondria.

Mitochondrial preservation can be mediated by $\mu$ and $\delta_{2}$ ORs signalling

What is the relationship between activation of ORs and preservation of the functional state of mitochondria of adapted rats after $\mathrm{I} / \mathrm{R}$ exposure? It has been documented that stimulation of ORs results in the activation of PI3K/Akt (Maslov et al. 2016) which in turn phosphorylates p70s6K and GSK3 $\beta$ (Heusch et al. 2015). The involvement of the PI3K/GSK-3 $\beta$ pathway in OR-mediated cytoprotection was recently reported by Skrabalova et al. (2018). The end result of this signaling pathway is the blockade of the MPT pore opening (Heusch et al. 2015, Ong SB et al. 2015). We hypothesize that these events occur in the cardiomyocyte after $\mathrm{CNH}$.

The results of the present study demonstrate that adaptation to $\mathrm{CNH}$ increased the tolerance of an isolated heart to the $I / R$ injury which results in decreased $C K$ release and improved recovery of contractile function during reperfusion. $\mathrm{CNH}$ did not affect mitochondrial function in hearts not subjected to $I / R$, but it suppressed the damaging effects of $\mathrm{I} / \mathrm{R}$ on mitochondrial respiration, $\mathrm{ADP} / \mathrm{O}$ ratio, $\Delta \psi$ and the susceptibility of MPTP to opening. Consequently, the myocardial ATP level fully recovered during reperfusion and the recovery of cardiac contractility improved and necrosis of cardiomyocytes decreased. These protective effects of $\mathrm{CNH}$ are likely to be mediated via $\mu$ and $\delta_{2}$ OR activation.

\section{Conflict of Interest}

There is no conflict of interest. 


\section{Acknowledgements}

The authors express their gratitude to the Dr. Kevin J. Gormley (Division of Neuroscience and Behavioral Research, NIDA, NIH, Bethesda, Maryland) for providing the peptides (CTAP, TIPP $(\psi))$.
This study was supported by Russian Science Foundation Grant 16-15-10001. Experiments with CTAP were conducted within the framework of the state assignment AAAA-A15-115120910024-0.

\section{References}

ABDELWAHID E, STULPINAS A, KALVELYTE A: Effective agents targeting the mitochondria and apoptosis to protect the heart. Curr Pharm Des 23: 1153-1166, 2017.

ARGAUD L, GATEAU-ROESCH O, MUNTEAN D, CHALABREYSSE L, LOUFOUAT J, ROBERT D, OVIZE M: Specific inhibition of the mitochondrial permeability transition prevents lethal reperfusion injury. $J$ Mol Cell Cardiol 38: 367-374, 2005.

BRADFORD MM: A rapid and sensitive method for the quantities of microgram quantities of protein utilized the principle of protein day binding. Anal Biochem 72: 248-254, 1976.

BU HM, YANG CY, WANG ML, MA HJ, SUN H, ZHANG Y: $\mathrm{K}_{\text {ATP }}$ channels and MPTP are involved in the cardioprotection bestowed by chronic intermittent hypobaric hypoxia in the developing rat. J Physiol Sci $\mathbf{6 5}$ : 367-376, 2015.

BUZAS B, IZENWASSER S, PORTOGHESE PS, COX BM: Evidence for delta opioid receptor subtypes regulating adenylyl cyclase activity in rat brain. Life Sci 54: PL101-PL106, 1994.

CADET P, MANTIONE KJ, STEFANO GB: Molecular identification and functional expression of $\mu_{3}$, a novel alternatively spliced variant of the human $\mu$ opiate receptor gene. J Immunol 170: 5118-5123, 2003.

CHANCE B, WILLIAMS GR: Respiratory enzymes in oxidative phosphorylation. III. The steady state. $J$ Biol Chem 217: 409-427, 1955.

CHEN X, JENNINGS DB, MEDEIROS DM: Impaired cardiac mitochondrial membrane potential and respiration in copper-deficient rats. J Bioenerg Biomembr 34: 397-406, 2002.

CHOWDHURY SR, DJORDJEVIC J, ALBENSI BC, FERNYHOUGH P: Simultaneous evaluation of substratedependent oxygen consumption rates and mitochondrial membrane potential by TMRM and safranin in cortical mitochondria. Biosci Rep 36: e00286, 2015.

COHEN MV, DOWNEY JM: Is it time to translate ischemic preconditioning's mechanism of cardioprotection into clinical practice? J Cardiovasc Pharmacol Ther 16: 273-80, 2011.

EELLS JT, HENRY MM, GROSS GJ, BAKER JE: Increased mitochondrial K(ATP) channel activity during chronic myocardial hypoxia: is cardioprotection mediated by improved bioenergetics? Circ Res 87: 915-921, 2000.

ESSOP MF, RAZEGHI P, MCLEOD C, YOUNG ME, TAEGTMEYER H, SACK MN Hypoxia-induced decrease of UCP3 gene expression in rat heart parallels metabolic gene switching but fails to affect mitochondrial respiratory coupling. Biochem Biophys Res Commun 314: 561-564, 2004.

FICHNA J, STANISZEWSKA R, POELS J, VANDEN BROECK J, JANECKA A: $\mu$-Opioid receptor ligands lack receptor subtype selectivity in the aequorin luminescence-based calcium assay. Chem Biol Drug Des 70: 247-253, 2007.

FITZPATRICK CM, SHI Y, HUTCHINS WC, SU J, GROSS GJ, OSTADAL B, TWEDDELL JS, BAKER JE: Cardioprotection in chronically hypoxic rabbits persists on exposure to normoxia: role of NOS and $\mathrm{K}_{\mathrm{ATP}}$ channels. Am J Physiol Heart Circ Physiol 288: H62-H68, 2005.

GARCIA-BARRADO MJ, IGLESIAS-OSMA MC, RODRÍGUEZ R, MARTÍN M, MORATINOS J: Role of $\mu$-opioid receptors in insulin release in the presence of inhibitory and excitatory secretagogues. Eur J Pharmacol 448: 95-104, 2002.

GOMEZ L, PAILLARD M, THIBAULT H, DERUMEAUX G, OVIZE M: Inhibition of GSK3 $\beta$ by postconditioning is required to prevent opening of the mitochondrial permeability transition pore during reperfusion. Circulation 117: 2761-2768, 2008. 
GROSS GJ, HSU A, NITHIPATIKOM K, BOBROVA I, BISSESSAR E: Eribis peptide 94 reduces infarct size in rat hearts via activation of centrally located $\mu$ opioid receptors. J Cardiovasc Pharmacol 59: 194-197, 2012.

HALESTRAP AP, CLARKE SJ, KHALIULIN I: The role of mitochondria in protection of the heart by preconditioning. Biochim Biophys Acta 1767: 1007-1031, 2007.

HAUSENLOY DJ, KUNST G, BOSTON-GRIFFITHS E, KOLVEKER S, CHAUBEY S, JOHN L, DESAI J, YELLON D: The effect of cyclosporin-A on peri-operative myocardial injury in adult patients undergoing coronary artery bypass graft surgery: a randomised controlled clinical trial. Heart 100: 544-549, 2014.

HEADRICK JP, SEE HOE LE, DU TOIT EF, PEART JN: Opioid receptors and cardioprotection - 'opioidergic conditioning' of the heart. Br J Pharmacol 172: 2026-2050, 2015.

HEATHER LC, COLE MA, TAN JJ, AMBROSE LJ, POPE S, ABD-JAMIL AH, CARTER EE, DODD MS, YEOH KK, SCHOFIELD CJ, CLARKE K: Metabolic adaptation to chronic hypoxia in cardiac mitochondria. Basic Res Cardiol 107: 268, 2012.

HEIJNA MH, PADT M, HOGENBOOM F, PORTOGHESE PS, MULDER AH, SCHOFFELMEER AN: Opioid receptor-mediated inhibition of dopamine and acetylcholine release from slices of rat nucleus accumbens, olfactory tubercle and frontal cortex. Eur J Pharmacol 181: 267-278, 1990.

HEUSCH G: Molecular basis of cardioprotection: signal transduction in ischemic pre-, post-, and remote conditioning. Circ Res 116: 674-699, 2015.

KROEMER G, GALLUZZI L, BRENNER C: Mitochondrial membrane permeabilization in cell death. Physiol Rev 87: 99-163, 2007.

MASLOV LN, KHALIULIN I, OELTGEN PR, NARYZHNAYA NV, PEI JM, BROWN SA, LISHMANOV YB, DOWNEY JM: Prospects of creation of cardioprotective and antiarrhythmic drugs based on opioid receptor agonists. Med Res Rev 36: 871-923, 2016.

MASLOV LN, LISHMANOV YB, OELTGEN PR, BARZAKH EI, KRYLATOV AV, NARYZHNAYA NV, PEI JM, BROWN SA: Comparative analysis of the cardioprotective properties of opioid receptor agonists in a rat model of myocardial infarction. Acad Emerg Med 17: 1239-1246, 2010.

MASLOV LN, LISHMANOV YuB, OELTGEN PR, BARZAKH EI, KRYLATOV AV, GOVINDASWAMI M, BROWN SA: Activation of peripheral $\delta_{2}$ opioid receptors increases cardiac tolerance to ischemia/reperfusion injury: Involvement of protein kinase $\mathrm{C}$, NO-synthase, $\mathrm{K}_{\mathrm{ATP}}$ channels and the autonomic nervous system. Life Sci 84: 657-663, 2009.

MASLOV LN, NARYZHNAYA NV, PROKUDINA ES, KOLAR F, GORBUNOV AS, ZHANG Y, WANG H, TSIBULNIKOV SYu, PORTNICHENKO AG, LASUKOVA TV, LISHMANOV: YuB Preserved cardiac mitochondrial function and reduced ischemia/reperfusion injury afforded chronic continuous hypoxia: role of opioid receptors. Clin Exp Pharmacol Physiol 42: 496-501, 2015.

MASLOV LN, NARYZHNAYA NV, TSIBULNIKOV SYu, KOLAR F, ZHANG Y, WANG H, GUSAKOVA AM, LISHMANOV: YuB Role of endogenous opioid peptides in the infarct size-limiting effect of adaptation to chronic continuous hypoxia. Life Sci 93: 373-379, 2013.

MUKHOMEDZYANOV AV, MASLOV LN, TSIBULNIKOV SY, PEI JM: Endomorphins and $\beta$-endorphin do not affect heart tolerance to the pathogenic effect of reperfusion. Bull Exp Biol Med 162: 23-26, 2016.

NECKAR J, SZARSZOI O, HERGET J, OSTADAL B, KOLAR F: Cardioprotective effect of chronic hypoxia is blunted by concomitant hypercapnia. Physiol Res 52: 171-175, 2003.

NECKAR J, SZARSZOI O, KOTEN L, PAPOUSEK F, OST'ADAL B, GROVER GJ, KOLAR F: Effects of mitochondrial $\mathrm{K}_{\mathrm{ATP}}$ modulators on cardioprotection induced by chronic high altitude hypoxia in rats. Cardiovasc Res 55: 567-575, 2002.

NECKAR J, SVATOŇOVÁ A, WEISSOVÁ R, DRAHOTA Z, ZAJÍČKOVÁ P, BRABCOVÁ I, KOLÁŘ D, ALÁNOVÁ P, VAŠINOVÁ J, ŠILHAVÝ J, HLAVÁČKOVÁ M, TAUCHMANNOVÁ K, MILEROVÁ M, OŠŤÁDAL B, ČERVENKA L, ŽURMANOVÁ J, KALOUS M, NOVÁKOVÁ O, NOVOTNÝ J, PRAVENEC M, KOLÁŘ F: Selective replacement of mitochondrial DNA increases the cardioprotective effect of chronic continuous hypoxia in spontaneously hypertensive rats. Clin Sci (Lond) 131: 865-881, 2017.

ONG SB, DONGWORTH RK, CABRERA-FUENTES HA, HAUSENLOY DJ: Role of the MPTP in conditioning the heart - translatability and mechanism. Br J Pharmacol 172: 2074-2084, 2015. 
ORTIZ-MIRANDA SI, DAYANITHI G, COCCIA V, CUSTER EE, ALPHANDERY S, MAZUC E, TREISTMAN S, LEMOS JR: $\mu$-Opioid receptor modulates peptide release from rat neurohypophysial terminals by inhibiting $\mathrm{Ca}^{2+}$ influx. J Neuroendocrinol 15: 888-894, 2003.

OSTADAL B, KOLAR F: Cardiac Ischemia: From Injury to Protection. B. OSTADAL, F. KOLAR (Eds.). Boston, Dordrecht, London: Kluwer Academic Publishers 173, 1999.

PAILLARD M, GOMEZ L, AUGEUL L, LOUFOUAT J, LESNEFSKY EJ, OVIZE M: Postconditioning inhibits mPTP opening independent of oxidative phosphorylation and membrane potential. J Mol Cell Cardiol 46: 902-909, 2009.

PANICKAR KS, POLANSKY MM, GRAVES DJ, URBAN JF jr, ANDERSON RA A: procyanidin type A trimer from cinnamon extract attenuates glial cell swelling and the reduction in glutamate uptake following ischemia-like injury in vitro. Neuroscience 202: 87-98, 2012.

PEART JN, GROSS GJ: Exogenous activation of $\delta$ - and $\kappa$-opioid receptors affords cardioprotection in isolated murine heart. Basic Res Cardiol 99: 29-37, 2004.

PEART JN, PATEL HH, GROSS GJ: Delta-opioid receptor activation mimics ischemic preconditioning in the canine heart. J Cardiovasc Pharmacol 42: 78-81, 2003.

PORTOGHESE PS, SULTANA M, NAGASE H, TAKEMORI AE: A highly selective $\delta_{1}$-opioid receptor antagonist: 7-benzylidenenaltrexone. Eur J Pharmacol 218: 195-196, 1992.

REDDY CA, SOMEPALLI V, GOLAKOTI T, KANUGULA AK, KARNEWAR S, RAJENDIRAN K, VASAGIRI N, PRABHAKAR S, KUPPUSAMY P, KOTAMRAJU S, KUTALA VK: Mitochondrial-targeted curcuminoids: a strategy to enhance bioavailability and anticancer efficacy of curcumin. PLos One 9: e89351, 2014.

RASOLA A, BERNARDI P: Mitochondrial permeability transition in $\mathrm{Ca}^{2+}$-dependent apoptosis and necrosis. Cell Calcium 50: 222-233, 2011.

SAKURADA S, WATANABE H, HAYASHI T, YUHKI M, FUJIMURA T, MURAYAMA K, SAKURADA C, SAKURADA T: Endomorphin analogues containing D-Pro ${ }^{2}$ discriminate different $\mu$-opioid receptor mediated antinociception in mice. Br J Pharmacol 137: 1143-1146, 2002.

SAKURADA S, ZADINA JE, KASTIN AJ, KATSUYAMA S, FUJIMURA T, MURAYAMA K, YUKI M, UEDA H, SAKURADA T: Differential involvement of $\mu$-opioid receptor subtypes in endomorphin-1- and -2-induced antinociception. Eur J Pharmacol 372: 25-30, 1999.

SANCHEZ-BLAZQUEZ P, RODRÍGUEZ-DÍAZ M, FREJO MT, GARZÓN J: Stimulation of $\mu$ - and $\delta$-opioid receptors enhances phosphoinositide metabolism in mouse spinal cord: evidence for subtypes of $\delta$-receptors. Eur J Neurosci 11: 2059-2064, 1999.

SANDERSON TH, REYNOLDS CA, KUMAR R, PRZYKLENK K, HUTTEMANN M Molecular mechanisms of ischemia-reperfusion injury in brain: pivotal role of the mitochondrial membrane potential in reactive oxygen species generation. Mol Neurobiol 47: 9-23, 2013.

SCADUTO RC, GROTYOHANN LW: Measurement of mitochondrial membrane potential using fluorescent rhodamine derivatives. Biophys J 76: 469-477, 1999.

SCHERRER G, BEFORT K, CONTET C, BECKER J, MATIFAS A, KIEFFER BL: The delta agonists DPDPE and deltorphin II recruit predominantly mu receptors to produce thermal analgesia: a parallel study of mu, delta and combinatorial opioid receptor knockout mice. Eur J Neurosci 19: 2239-2248, 2004.

SCHILLER PW, WELTROWSKA G, NGUYEN TM, WILKES BC, CHUNG NN, LEMIEUX C TIPP $(\psi)$ : a highly potent and stable pseudopeptide $\delta$ opioid receptor antagonist with extraordinary $\delta$ selectivity. $J$ Med Chem 36: 3182-3187, 1993.

SCHULTZ JE, HSU AK, GROSS GJ: Ischemic preconditioning in the intact rat heart is mediated by $\delta_{1}$ - but not $\mu$ - or K-opioid receptors. Circulation 97: 1282-1289, 1998.

SEIDLMAYER LK, JUETTNER VV, KETTLEWELL S, PAVLOV EV, BLATTER LA, DEDKOVA EN: Distinct mPTP activation mechanisms in ischaemia-reperfusion: contributions of $\mathrm{Ca}^{2+}, \mathrm{ROS}, \mathrm{pH}$, and inorganic polyphosphate. Cardiovasc Res 106: 237-248, 2015.

SINGH IN, SULLIVAN PG, DENG Y, MBYE LH, HALL ED: Time course of post-traumatic mitochondrial oxidative damage and dysfunction in a mouse model of focal traumatic brain injury: implications for neuroprotective therapy. J Cereb Blood Flow Metab 26: 1407-1418, 2006. 
SKRABALOVA J, KARLOVSKA I, HEJNOVA L, NOVOTNY J: Protective effect of morphine against the oxidantinduced injury in H9c2 cells. Cardiovasc Toxicol 18: 374-385, 2018.

TAJIMA M, KATAJOSE D, BESSHO M, ISOYAMA S: Acute ischemic preconditioning and chronic hypoxia independently increase myocardial tolerance to ischemia. Cardiovasc Res 28: 312-319, 1994.

TANG T, KIANG JG, COX BM: Opioids acting through delta receptors elicit a transient increase in the intracellular free calcium concentration in dorsal root ganglion-neuroblastoma hybrid ND8-47 cells. J Pharmacol Exp Ther 270: 40-46, 1994.

TATOULIS J, WYNNE R, SKILLINGTON PD, BUXTON BF: Total arterial revascularization: achievable and prognostically effective - a multicenter analysis. Ann Thorac Surg 100: 1268-1275, 2015.

TSIBULNIKOV SY, MASLOV LN, MUKHOMEDZYANOV AV, KRYLATOV AV, TSIBULNIKOVA MR, LISHMANOV YB: Prospects of using of $\kappa$-opioid receptor agonists U-50,488 and ICI 199,441 for improving heart resistance to ischemia/reperfusion. Bull Exp Biol Med 159: 718-721, 2015.

WANG Y, LIU X, WANG D, YANG J, ZHAO L, YU J, WANG R: Endomorphin-1 analogues (MELs) penetrate the blood-brain barrier and exhibit good analgesic effects with minimal side effects. Neuropharmacology 97: 312-321, 2015.

WANG ZH, CAI XL, WU L, YU Z, LIU JL, ZHOU ZN, LIU J, YANG HT: Mitochondrial energy metabolism plays a critical role in the cardioprotection afforded by intermittent hypobaric hypoxia. Exp Physiol 97: 1105-1118, 2012.

ZHANG WP, ZONG QF, GAO Q, YU Y, GU XY, WANG Y, LI ZH, GE M: Effects of endomorphin-1 postconditioning on myocardial ischemia/reperfusion injury and myocardial cell apoptosis in a rat model. $\mathrm{Mol}$ Med Rep 14: 3992-3998, 2016.

ZHU WZ, XIE Y, CHEN L, YANG HT, ZHOU ZN: Intermittent high altitude hypoxia inhibits opening of mitochondrial permeability transition pores against reperfusion injury. J Mol Cell Cardiol 40: 96-106, 2006.

ZUNGU M, ALCOLEA MP, GARCIA-PALMER FJ, YOUNG ME, ESSOP MF: Genomic modulation of mitochondrial respiratory genes in the hypertrophied heart reflects adaptive changes in mitochondrial and contractile function. Am J Physiol Heart Circ Physiol 293: H2819-H2825, 2007.

WONG GT, YAO L, XIA Z, IRWIN MG Intrathecal morphine remotely preconditions the heart via a neural pathway. J Cardiovasc Pharmacol 60: 172-178, 2012. 